$\underline{\xi}=-m$

\title{
Liquorice (glycyrrhiza glabra) hydroethanolic extracts effectively alleviate thioacetamide -induced hepatotoxicity and hematotoxicity in experimental rats through their antioxidant nature
}

\author{
Alaa Behairy ${ }^{1 *}$, Ashraf Elkomy ${ }^{1}$, Faten Elsayed ${ }^{1}$ \\ ${ }^{1}$ Department of Pharmacology, Faculty of Veterinary Medicine, Benha University, 13736 Moshtohor, Qaliobiya, Egypt \\ *Corresponding authorE-mail: alaa.behairy@fvtm.bu.edu.eg
}

\begin{abstract}
Background: Liquorice (Glycyrrhiza glabra) is a high valued plant and used in a lot of countries around the world. The liquorice (LQ) has a remarkable medicinal, nutritional and socio-economic value. Therefore this study was designed to clarify the protective effect of liquorice hydroethanolic extract against Thioacetamide (TAA) induced hepatotoxicity and hematotoxicity in rats.

Materials and Methods: Seventy white Albino male rats were used in this study and after acclimatization rats were subjected to different treatments blood and tissue samples were collected after day 30 post administration, biochemical, antioxidant, hematological and histopathological examinations were utilized to investigate hepatoprotective activity of liquorice hydroethanolic extract.

Results: TAA significant $(\mathrm{P}<0.05)$ increase the activities of aspartate aminotransferase (AST), alanine aminotransferase (ALT), alkaline phosphatase (ALP) and hepatic malondialdehyde (MDA) compared to control group and silymarin(SL)treated group as stander, administration of LQ extract restore the toxic effect of TAA, while TAA significant $(\mathrm{P}<0.05)$ decrease the levels of catalase $(\mathrm{CAT})$, hepatic glutathione(GSH) hepatic superoxide dismutase (SOD), total protein and albumin level compared to control group and silymarin(SL)treated group as stander, LQ extract ameliorate toxic effect of TAA. TAA induce hematotoxicity in rats by significant $(\mathrm{P}<0.05)$ decrease $\mathrm{Hb}$ content and RBCs, whereas WBCs count significantly $(\mathrm{P}<0.05)$ increased throughout the period of administration when compared to the rats in control group and silymarin(SL)treated group as stander,LQ administration protect against the hematotoxicity effect of TAA, TAA induce histopathological alteration in liver tissue by comparison with control group and silymarin(SL)treated group as stander, while LQ extract showing improvement in the histopathological lesion compared with toxic effect induced by TAA. Conclusions: The hepatotoxicity and hematotoxicity induced by TAA were ameliorated by hydroethanolic extract of LQ especially in double dose $(200 \mathrm{mg} / \mathrm{kg}$ b.wt). This effect was attributed to free radical scavenging activity and potent antioxidant activity of its components (flavonoid, tannin and saponin).
\end{abstract}

Keywords: Hematotoxicity; Hepatotoxicity; Liquorice Extract; Rats; Thioacetamide.

\section{Introduction}

Liver disease is considered great public health trouble on a global scale. In spite of modern drugs have been utilizing to treat liver disturbances, these drugs have often side effects. Thence, advanced research studies have been performed to explore the safe and potent therapies without side effects to treat liver disorders. Natural therapies from medicinal plants are consider the most desirable and ravishing area as alternative treatment for hepato-toxicity,hepatoprotective effects of plants are related with phytocompounds rich in natural antioxidants as glycosides, saponin, flavonoids, tannin, alkaloids, vitamin A, C, E and other phenolic compounds. (Biomy et al., 2018) Liquorice (Family: Leguminosae) is a valuable plant. It is widely distributed in a lot of countries of the world; liquorice is a perennial herb native to Mediterranean region, central to southern Russia and Asia Minor to Iran (Dastagir and Rizvi, 2016). Liquorice (LQ) is a good source of sugar, salts, minerals (calcium, potassium, phosphorus, and magnesium), phytochemical compound (glycosides, flavonoids, saponin and tannins) (Thakur et al., 2016)

In traditional medicine, LQ has been used for management of various liver disorders. Thence, this study was designed to demonstrate the hepatic and hematological effects of LQ against TAA toxicity through determination of liver function, antioxidant activity, hematological and histopathological examination and these results will further support the protective effect of LQ and will clarify the capacity of this plant in medication of liver diseases by a comparison with silymarin. 


\section{Materials and methods}

\subsection{Liquorice}

Liquorice was purchased from local market, Benha City, Qalubiya Governrate, Egypt. The plant was identified in Department of Botany, FacuIty of science, Cairo University. It was given in a two doses $(100 \mathrm{mg} / \mathrm{kg}$ b.wt and $200 \mathrm{mg} / \mathrm{kg}$ b.wt $)$ orally for 30 day for hepatoproductive effect (Shalaby et al., 2004)

\subsection{Drugs}

\subsubsection{Silymarin (hepaticum $\left.{ }^{\circledR}\right)$}

Is a micronized silymarin, silybin in the form of dry standardized extract of milk thistle plant (Silybum marianum). Each $100 \mathrm{ml}$ suspension contains $1 \mathrm{gm}$ silymarin standardized to a content of more than $45 \%$ silybin $(50 \mathrm{mg} / 5 \mathrm{ml})$. It was obtained from Medical Union Pharmaceuticals (MUP) Company, Abu-Sultan, Ismailia, Egypt .It was used in a dose of $50 \mathrm{mg} / \mathrm{kg}$ b.wt (Adhikari and Arora, 2016) and (Raj et al., 2010)

\subsubsection{Thioacetamide}

Is one of the most common hepatotoxin used for experimental induction of liver injury in animal studies. It was obtained from Merck KGaA (Darmstadt, Germany) via a local distributor, given in a dose $100 \mathrm{mg} / \mathrm{kg}$ b.wt intraperitoneally twice weekly for 30 day (Gheith and El-mahmoudy, 2019).

\subsection{Preparation of hydro-ethanolic extract of liquorice}

Liquorice was refluxed with bi-distilled water, shade dried at room temperature and coarsely crushed using a pestle and mortar, Extract were prepared according to modified method of Harborne, (1973). A dark brown mass was obtained. It re-constituted by dissolving in measured amount hydro ethanol (30\%). The extract was stored in air tight container in refrigerator below $10{ }^{\circ} \mathrm{C}$. For in vivo studies, a stock solution was made so that each rat receives the calculated dose in $1 \mathrm{~mL}$ solvent. Percentage yield was determined using the formula.

Yield $\%=\frac{\text { weight of extract }}{\text { weight of plant material }} \times 100$

\subsection{Preparation of thioacetamide for administration}

Thioacetamide powder was dissolved in saline at concentration of $40 \mathrm{mg} / \mathrm{ml}$. The standard hepatotoxic dose of thioacetamide is 100 $\mathrm{mg} / \mathrm{kg}$ (Yan-yu et al., 2006). So, a rat weighing $200 \mathrm{gm}$ was injected intraperitoneally with $0.5 \mathrm{ml}$ of the prepared solution (40 mg/ml), equivalent to $100 \mathrm{mg} / \mathrm{kg}$ b.wt

\subsection{Preparation of silymarin (Hepaticum $\left.{ }^{\circledR}\right)$ for administration}

Silymarin was used as such without dilution, where a rat weighing $200 \mathrm{~g}$ receives $1 \mathrm{ml}$ of Hepaticum® suspention, equivalent to 50 $\mathrm{mg} / \mathrm{kg}$ b.wt. (Yan-yu et al., 2006)

\subsection{Rats and experimental design}

Male Wister albino rats weighing 150-200gm were obtained from animal house, Faculty of Veterinary Medicine, Benha University, Egypt. They were fed standard pellet food and given access water. Rats were kept at a constant environmental and nutritional condition for 15 days for acclimatization before the beginning of the experiment. Seventy rats were randomly divided into main 7 groups ten rats in each.

Group (1): which served as normal control and received isotonic saline solution once orally for 30 day .Group (2): treated with small dose of LQ extract (100 mg/kg b.wt) for 30 day. Group (3): treated with large dose of LQ extract (200 mg/kg b.wt) for 30 day. Group (4): intoxicated with TAA $(100 \mathrm{mg} / \mathrm{kg}$ b.wt) intraperitoneally twice weekly for 30 day to induce liver injury. Group (5): administrated small dose of LQ extract $(100 \mathrm{mg} / \mathrm{kg}$ b.wt) followed by intraperitoneal injection of TAA in a dose of $100 \mathrm{mg} / \mathrm{kg}$ b.wt, twice weekly for 30 day. Group (6): treated with large dose of LQ extract ( $200 \mathrm{mg} / \mathrm{kg} \mathrm{b.wt)}$ followed by intraperitoneal injection of TAA in a dose of $100 \mathrm{mg} / \mathrm{kg}$ b.wt., twice weekly for 30 day. Group (7): administrated silymarin (Hepaticum ${ }^{\circledR}$ ) orally in a dose of $50 \mathrm{mg} / \mathrm{kg}$ b.wt. ,daily for 30 day followed by intraperitoneal injection of TAA in a dose of $100 \mathrm{mg} / \mathrm{kg} \mathrm{b}$.wt., twice weekly for 30 day.

\subsection{Sampling}

Samples were taken post-treatment in all groups. Two blood samples were taken from each rat in the group for both biochemical and hematological studies from median canthus of the eye. The first blood sample was collected without anticoagulant for separation of clear serum for biochemical analysis. These serum samples were used for biochemical analysis to determine, serum aspartate aminotransferase activity (AST), serum alanine aminotransferase activity (ALT), alkaline phosphatase (ALP), total protein and albumin. The second sample of blood was collected in the test tube mixed with sodium citrate $3.8 \%$ as anticoagulant. The sample was shaked several times to ensure mixing of blood with anticoagulant. These blood samples were used for hematological studies to determine erythrocytic count, total leukocyte count and haemoglobin concentration.

Preparation of liver homogenate immediately after blood sampling. Livers were collected for biochemical and histopathological examinations. Liver tissues were rapidly removed, washed in ice-cooled saline, plotted dry and weighed. Then it was homogenized by electric 
homogenizer. The homogenate was centrifuge at 3,000rpm for 5 minutes. Then the homogenate centrifuged again in cooling centrifuge for excluding debris from the homogenate.

\subsection{Serum biochemical analysis}

Aspartate aminotransferase, alanine aminotransferase, alkaline phosphatase, protein and albumin levels were determined in serum spectro-photometrically by specific kits (Centronic Company®, Germany). Determination of AST, ALT according to Reitman and Frankel, (1957), Determination of ALP according to Haussament, (1977) and Determination of total protein and albumin level according to Doumas et al., (1971)

\subsection{Evaluation of oxidative stress biomarker in liver}

Determination of CAT according to Aebi, (1984), Determination of GSH according to Beutler, (1963), Determination of SOD according to Nishikimi et al., (1972) and Determination of MDA according to Ohkawa et al., (1979).

\subsection{Hematological study}

Hemoglobin concentration, erythrocyte count and white blood cells were counted by using automatic blood cell counter (model HA-VET CLINDIAG).

\subsection{Histopathology study}

Autopsy samples were taken from the liver of rats in several groups and fixed in 10\% formalin saline for 7 days, after completion of fixation, the samples were dehydrated in a series of alcohols, cleared in toluene and then embedded in paraplast (Sherweed Medical Co, USA). Blocks were cut at 5-7 $\mu \mathrm{m}$. Sections were de-waxed, re-hydrated in a series of alcohols, stained in Harris hematoxylin (Cole Parmer, USA) and counterstained in $1 \%$ aqueous eosin (Sigma, USA). Sections were then mounted in DePeX (GURR, BDH, UK) and examined under a light microscope. Representative slides were photographed under an Olympus Vanox photomicroscope (Olympus, USA) (Al-Naqeeb et al., 2003)

\subsection{Statistical analysis}

Statistical analysis was conducted with the Statistical Package for Social Science (SPSS 16 Inc. Released, 2009) to determine if variables differed among groups, Comparison among means was conducted by one-way ANOVA and subsequent Ducann's multiple range test,Probability values of less than $5 \%(\mathrm{p} \leq 0.05)$ were considered significant.

\section{Results}

LQ hydroethanolic extract (30\%) was brown in color with semisolid texture. The extraction process gave a yield of $20.64 \%$ from 200 gm of the plant. TAA induced a significant $(\mathrm{P}<0.05)$ increase in the level of serum AST, ALT and ALP, compared to the control group and silymarin(SL)treated group as stander, administration of LQ extract at both doses with TAA restore the toxic effect of TAA (Table1.)

Table 1: The Effect of TAA And/Or LQ (Single And Double Doses) Or SL On Serum AST, ALT And ALP In Rats (N=9)

\begin{tabular}{llll}
\hline Groups/Parameter & AST (U/L) & ALT(U/L) & ALP(U/L) \\
\hline Control & $150.82 \pm 1.03^{\mathrm{e}}$ & $63.47 \pm 2.99^{\mathrm{e}}$ & $518.57 \pm 0.642^{\mathrm{d}}$ \\
$\mathrm{LQ}(100 \mathrm{mg} / \mathrm{kg})$ & $150.51 \pm 1.31^{\mathrm{e}}$ & $63.21 \pm 3.40^{\mathrm{e}}$ & $518.26 \pm 0.478^{\mathrm{d}}$ \\
$\mathrm{LQ}(200 \mathrm{mg} / \mathrm{kg})$ & $150.34 \pm 1.11^{\mathrm{e}}$ & $63.31 \pm 4.52^{\mathrm{e}}$ & $518.38 \pm 0.578^{\mathrm{d}}$ \\
TAA & $228.66 \pm 0.801^{\mathrm{a}}$ & $199.19 \pm 5.47^{\mathrm{a}}$ & $769.36 \pm 40.64^{\mathrm{a}}$ \\
TAA+LQ $(100 \mathrm{mg} / \mathrm{kg})$ & $209.88 \pm 0.438^{\mathrm{b}}$ & $134.85 \pm 2.18^{\mathrm{b}}$ & $691.44 \pm 0.866^{\mathrm{b}}$ \\
TAA+LQ $(200 \mathrm{mg} / \mathrm{kg})$ & $190.17 \pm 0.611^{\mathrm{c}}$ & $106.33 \pm 3.03^{\mathrm{c}}$ & $590.93 \pm 0.627^{\mathrm{c}}$ \\
TAA+SL & $170.22 \pm 0.704^{\mathrm{d}}$ & $75.10 \pm 1.07^{\mathrm{d}}$ & $520.10 \pm 0.306^{\mathrm{d}}$ \\
Potential\% against LQ $(100 \mathrm{mg} / \mathrm{kg})$ & $32.1 \%$ & $51.8 \%$ & $31.2 \%$ \\
Potential\% against LQ $(200 \mathrm{mg} / \mathrm{kg})$ & $65.8 \%$ & $74.3 \%$ & $71.5 \%$ \\
Protection\% against the TAA+LQ $(100 \mathrm{mg} / \mathrm{kg})$ & $8.2 \%$ & $32.3 \%$ & $10.1 \%$ \\
Protection\% against the TAA+LQ $(200 \mathrm{mg} / \mathrm{kg})$ & $16.8 \%$ & $46.6 \%$ & $23.1 \%$ \\
Protection\% against the TAA+SL & $25.5 \%$ & $62.2 \%$ & $32.3 \%$ \\
\hline
\end{tabular}

Values are presented as means \pm SE. Means within a column with different letter superscripts are significantly different. LQ (liquorice), TAA: thioacetamide treated group; SL: silymarin treated group. AST (aspartate aminotransferase), ALT (alanine aminotransferase), ALP (alkaline phosphatase)

The concentrations of total protein and albumin level was significantly $(\mathrm{P}<0.05)$ reduced in TAA group compared to control group and silymarin(SL)treated group as stander, administration of $200 \mathrm{mg} / \mathrm{kg}$ b.wt LQ extract with TAA for 30 day significantly improve level of total protein and albumin. (Table 2.)

TAA induced a significant $(\mathrm{P}<0.05)$ decreased in the level of hepatic CAT, GSH and SOD, While, significantly $(\mathrm{P}<0.05)$ elevated hepatic MDA compared to the control group and SL treated group as stander. LQ extract at both doses with TAA ameliorate toxic effect of TAA. (Figure 1.)

Table 2: The Effect of TAA And/Or LQ (Single And Double Doses) Or SL On Serum Total Protein And Albumin In Rats (N=9)

\begin{tabular}{lll}
\hline Groups/Parameter & Total protein $(\mathrm{g} / \mathrm{dl})$ & Albumin $(\mathrm{g} / \mathrm{dl})$ \\
\hline Control & $10.64 \pm 0.184^{\mathrm{a}}$ & $4.31 \pm 0.242^{\mathrm{d}}$ \\
LQ $(100 \mathrm{mg} / \mathrm{kg})$ & $10.61 \pm 0.262^{\mathrm{a}}$ & $4.71 \pm 0.239^{\mathrm{cd}}$ \\
LQ $(200 \mathrm{mg} / \mathrm{kg})$ & $10.21 \pm 0.269^{\mathrm{ab}}$ & $5.00 \pm 0.101^{\mathrm{bc}}$ \\
TAA & $4.45 \pm 0.096^{\mathrm{e}}$ & $3.03 \pm 0.108^{\mathrm{e}}$ \\
\hline
\end{tabular}




\begin{tabular}{lll}
\hline TAA+LQ $(100 \mathrm{mg} / \mathrm{kg})$ & $7.79 \pm 0.125^{\mathrm{d}}$ & $4.71 \pm 0.174^{\mathrm{cd}}$ \\
TAA+LQ $(200 \mathrm{mg} / \mathrm{kg})$ & $9.60 \pm 0.246^{\mathrm{c}}$ & $5.38 \pm 0.099^{\mathrm{ab}}$ \\
TAA+SL & $9.83 \pm 0.123^{\mathrm{bc}}$ & $5.54 \pm 0.187^{\mathrm{a}}$ \\
Potential\% against LQ $(100 \mathrm{mg} / \mathrm{kg})$ & $62 \%$ & $66.9 \%$ \\
Potential\% against LQ $(200 \mathrm{mg} / \mathrm{kg})$ & $95.7 \%$ & $93.6 \%$ \\
Protection\% against the TAA+LQ $(100 \mathrm{mg} / \mathrm{kg})$ & $31.3 \%$ & $38.9 \%$ \\
Protection\% against the TAA+LQ $(200 \mathrm{mg} / \mathrm{kg})$ & $48.4 \%$ & $54.5 \%$ \\
Protection\% against the TAA+SL & $50.5 \%$ & $58.2 \%$ \\
\hline
\end{tabular}

Values are presented as means \pm SE. Means within a column with different letter superscripts are significantly different. LQ (liquorice), TAA: thioacetamide treated group; SL: silymarin treated group.
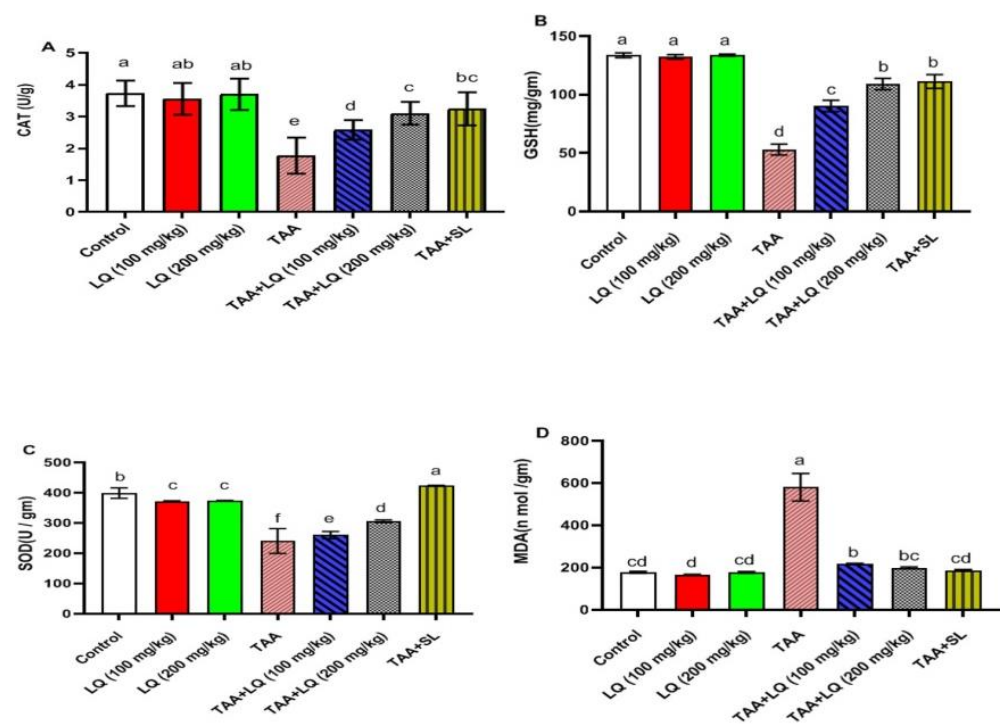

Fig. 1: Changes In Antioxidant Status Of Hepatic Tissue In Rats After Repeated (Twice Weekly, For 30 Day) I.P. Injection Of TAA (100mg/kg b.wt Dissolved In Isohaline) And Liquorice Hydroethanolic Extract At Both Dose In Comparison With Control Group And Silymarin Treated Group As Stander; Mean \pm SE, $(\mathrm{N}=9) * \mathrm{P}<0.05$. LQ (Liquorice); TAA: Thioacetamide Treated Group; SL: Silymarin Treated Group.CAT (Hepatic Catalase Level), GSH (Hepatic Glutathione Concentration), SOD (Hepatic Superoxide Dismutase Concentration), MDA (Hepatic Malondialdehyde Concentration)

The effect of the extract on hematological parameters of intoxicated rats by TAA was clearly shown on (Table 3.) TAA induced a significant $(\mathrm{P}<0.05)$ decreased in the level of $\mathrm{Hb}$ concentration and RBCs count, While, significantly $(\mathrm{P}<0.05)$ elevated WBCs count compared to the control group and SL treated group as stander. LQ extract at both doses with TAA protect against the hematotoxicity effect of TAA.

Table 3: The Effect of TAA And/Or LQ (Single And Double Doses) Or SL On Serum RBCs, HB And WBCs In Rats (N=9)

\begin{tabular}{|c|c|c|c|}
\hline Groups/Parameter & $\operatorname{RBCs}\left(10^{6} / \mu \mathrm{l}\right)$ & $\mathrm{HB}(\mathrm{g} / \mathrm{dl})$ & WBCs $\left(10^{3} / \mathrm{nmm}^{3}\right)$ \\
\hline Control & $6.54 \pm 0.094^{\mathrm{a}}$ & $13.18 \pm 0.153^{\mathrm{a}}$ & $8.94 \pm 0.311^{\mathrm{d}}$ \\
\hline LQ (100 mg/kg) & $6.07 \pm 0.051^{\mathrm{bc}}$ & $12.68 \pm 0.177^{\mathrm{a}}$ & $7.60 \pm 0.210^{\mathrm{e}}$ \\
\hline LQ $(200 \mathrm{mg} / \mathrm{kg})$ & $6.19 \pm 0.110^{\mathrm{ab}}$ & $12.64 \pm 0.243^{\mathrm{a}}$ & $7.40 \pm 0.408^{\mathrm{e}}$ \\
\hline TAA & $4.41 \pm 0.095^{\mathrm{e}}$ & $7.75 \pm 0.289^{\mathrm{e}}$ & $18.97 \pm 0.929^{\mathrm{a}}$ \\
\hline $\mathrm{TAA}+\mathrm{LQ}(100 \mathrm{mg} / \mathrm{kg})$ & $5.43 \pm 0.277^{\mathrm{d}}$ & $9.25 \pm 0.144^{\mathrm{d}}$ & $13.36 \pm 0.159^{b}$ \\
\hline TAA+LQ (200 mg/kg) & $5.70 \pm 0.205^{\mathrm{cd}}$ & $10.64 \pm 0.158^{c}$ & $11.41 \pm 0.204^{\mathrm{c}}$ \\
\hline $\mathrm{TAA}+\mathrm{SL}$ & $6.54 \pm 0.056^{\mathrm{a}}$ & $12.03 \pm 0.148^{b}$ & $10.36 \pm 0.114^{\mathrm{c}}$ \\
\hline Potential\% against LQ (100 mg/kg) & $47.8 \%$ & $35 \%$ & $65.1 \%$ \\
\hline $\begin{array}{l}\text { Protection } \% \text { against the TAA+LQ (100 } \\
\mathrm{mg} / \mathrm{kg})\end{array}$ & $15.5 \%$ & $11.3 \%$ & $29.5 \%$ \\
\hline $\begin{array}{l}\text { Protection } \% \text { against the TAA+LQ (200 } \\
\mathrm{mg} / \mathrm{kg})\end{array}$ & $19.7 \%$ & $21.9 \%$ & $39.8 \%$ \\
\hline Protection $\%$ against the $\mathrm{TAA}+\mathrm{SL}$ & $32.5 \%$ & $32.4 \%$ & $45.3 \%$ \\
\hline
\end{tabular}

Values are presented as means \pm SE. Means within a column with different letter superscripts are significantly different. LQ (liquorice); TAA: thioacetamide treated group; SL: silymarin treated group. RBCs (total erythrocytic count), HB (Hemoglobin concentration), WBCs (total leukocytic count)

Microscopical examination of different sections taken form specimens of Liver of control rats showed no histopathological alteration and the normal histological structure of the central vein and surrounding hepatocytes in the parenchyma (Figure 2A. ), while TAA group showed Inflammatory cells infiltration with fine fibroblastic cells proliferation were dividing the parenchyma into lobules in association with dilatation in the central vein (Figure 2B,C,D,E.), The portal area showed dilatation in the portal vein and inflammatory cells infiltration while the surrounding hepatocytes showed degenerative change (Figure $2 \mathrm{~F}$.), On contrast, Liver of group administered TAA+LQ $(100 \mathrm{mg} / \mathrm{kg})$ showed Centrilobular degeneration and necrobiosis in the hepatocytes with inflammatory cells infiltration in between were observed (Figure 2G.) While, Liver of group administered TAA+LQ (200 mg / kg) showed necrosis in the hepatocytes with inflammatory cells infiltration in the centrilobular zone of the parenchyma surrounding the central vein (Figure $2 \mathrm{H}$.), TAA+SL treated group showed, centrilobular inflammatory cells infiltration between the hepatocytes(Figure 2I. ) 

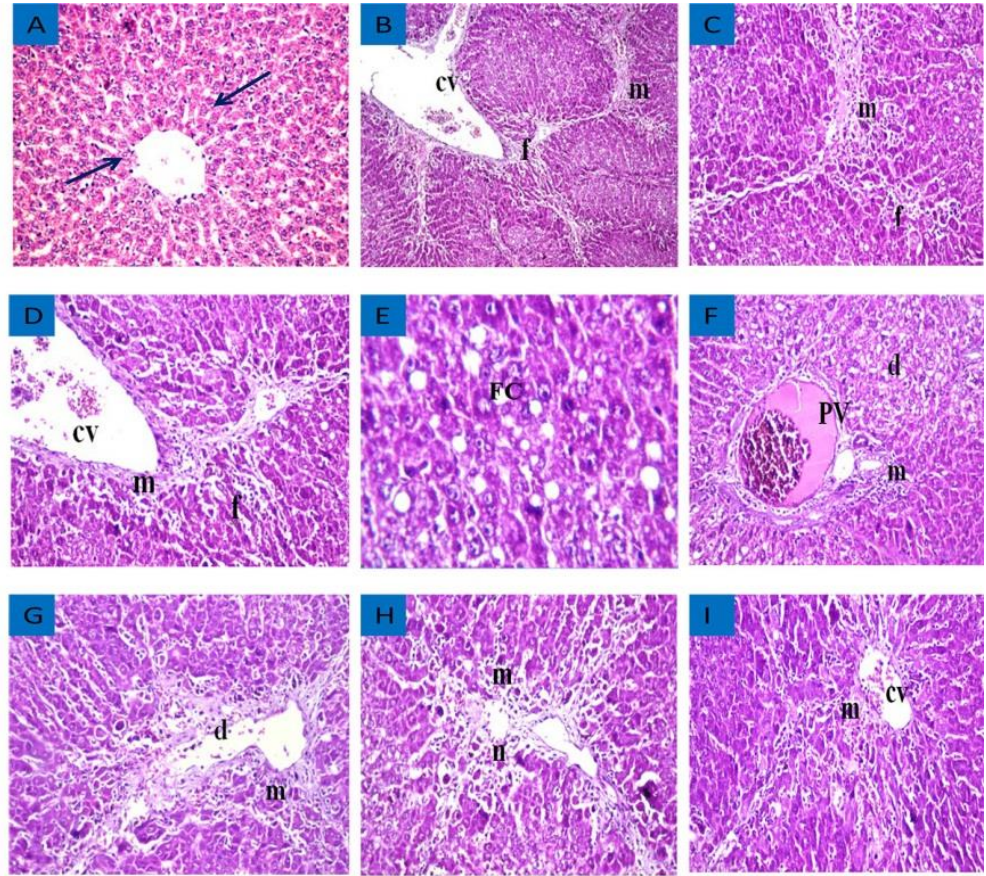

Fig. 2: Histopathological Changes Of Hepatic Tissue (A): Control Group Showed No Histopathological Alteration And The Normal Histological Structure Of The Central Vein And Surrounding Hepatocytes In The Parenchyma. (B): TAA Group Showed Inflammatory Cells Infiltration (m) With Fine Fibroblastic Cells Proliferation (f) Was Dividing The Parenchyma Into Lobules(X16). (C): Magnification Of (B) To Identify The Strands Of Fibroblast (f) And Inflammatory Cells Infiltration (m) In Between The Degenerated Hepatocytes(X40). (D): Magnification Of (B) To Identify The Dilated Central Vein (cv) And Strands Of Fibroblast (f) And Inflammatory Cells Infiltration (m) (X40). (E): TAA Group Showed Fatty Changed (FC) In Some Individual Hepatocytes) (X80). (F): TAA Group Showed Dilatation Of Portal Vein (PV) And Inflammatory Cells Infiltration (m) In Portal Area And Degeneration (d) In Surrounding Hepatocytes (X40). (G): TAA+LQ (100 mg/kg) Group Showed Centrilobular Degeneration And Necrobiosis (n) In The Hepatocytes With Inflammatory Cells Infiltration (m) In Between Were Observed (X40). (H): TAA+LQ (200 mg/kg) Group Showed Necrosis (n) In The Hepatocytes With Inflammatory Cells Infiltration (m) In The Centrilobular Zone Of The Parenchyma Surrounding The Central Vein (X40). (I): TAA+SL Group Showed Centrilobular Inflammatory Cells Infiltration (m) Was Detected In Between The Hepatocytes (X40).

Our findings revealed that treatment with LQ hydroethanolic extract at dose of $200 \mathrm{mg} / \mathrm{kg}$ b.wt and TAA appeared to have a remarkable effect than $100 \mathrm{mg} / \mathrm{kg}$ b.wt LQ hydroethanolic extract, as evidenced by return the levels of AST, ALT, ALP, total protein, albumin, CAT, GSH, SOD and MDA toward normal level. However, $200 \mathrm{mg} / \mathrm{kg}$ b.wt LQ hydroethanolic extract and TAA results of biochemical parameters nearly similar to SL and may be better in histopathological examination in which the ability of 200mg LQ hydroethanolic extract to reverse the hepatocellular injury induced by the TAA to a large extent compared to SL.

\section{Discussion}

Liver disease is one of the most common diseases spreading in the world, so researchers are interested to solve this problem. Administration of TAA in a dose of $100 \mathrm{mg} / \mathrm{kg}$ b.wt, twice weekly for 30 day induced hepatocellular damage as fatty degeneration and fibrosis, the mechanisms of TAA by which it causes liver injury are complex and remain poorly understood. TAA need oxidative bioactivation of its toxic metabolites to cause liver injury that affects both hepatocytes and cholangiocytes; TAA is reversibly metabolized to TAASO. In a second oxidation step, the highly reactive species TAASO2 is formed. Then, TAASO2 can directly react with amine groups (R-NH2) on cellular proteins or lipids resulting in dysfunction. In addition, TAA increase glutathione depletion and elevated levels of reactive oxygen species (ROS), lipid peroxides, cytotoxicity and mitochondrial injury. (Wallace et al., 2015). Hepatocellular damage induced by TAA causing leakage of AST and ALT into the circulation that is normally cytoplasmic in location. AST was found in mitochondria particularly in the centrilobular region of the liver while ALP is an ectoenzyme of the hepatocytes and its elevations in serum indicate membrane destruction. Liver is the main source of alkaline phosphatase but it is not a liver specific enzyme, while ALT was found in the hepatic parenchymal cells of the liver in large amount and regarded as more liver specific to test hepatocellular damage. (Amacher, 1998). Thus, AST, ALT and ALP are considered the best markers for detecting liver damage. Markers of hepatocellular damage (AST, ALT and ALP) increased significantly in the group intoxicated with TAA (Salam et al., 2013), (Kabiri et al., 2013) .Whereas, LQ extract markedly reduced the activities of these liver function enzymes, suggesting that LQ protective activity might be due its effect against cellular leakage and loss of functional integrity of the cell membrane in hepatocyte. Our results in accordance with that reported by Jing et al., (2015) who reported protective effect of LQ against TAA in rats, Also agreed with data reported by Rasool et al., (2014),administration of $200 \mathrm{mg} / \mathrm{kg}$ b. LQ extract appeared to have the best result than $100 \mathrm{mg} / \mathrm{kg}$ LQ extract when compared with SL treated group as stander.

TAA significantly reduce serum total protein and albumin level compared to control group and SL treated group as stander, Our results agree with El-Magd et al., (2015) who reported that TAA affected the liver function significantly as it decreased the ability of liver to synthesize the albumin and other proteins, TAA decreases the total protein in serum due to damage to the tissues, as The liver produces most plasma proteins in the body, Being a part of cell membrane and as an enzyme, protein participate the intricately balanced subcellular fractions, Protein plays a major role in the synthesis of microsomal detoxifying enzymes and helps to detoxify the toxicants which enter into the animal body(Das, 2014).administration of LQ hydroethanolic extract ameliorate total protein and albumin levels, Our results were similar to results detected by Goorani et al.,(2019) Who reported that aqueous extract of Glycyrrhiz aglabra enhance total protein and albumin.

TAA cause rise to the high level of ROS which cause destruction of antioxidant enzyme activities and considerably leads to oxidative stress. Oxidative stress in turn induces oxidative degeneration of membranes of hepatic cell to cause lipid peroxidation of the lipid mem- 
branes and leakage of biomarkers like malondialdehyde. The study results are consistent with a previous study in which the level of hepatic MDA greatly increased in TAA group compared to control group and SL treated group as stander. (Bashandy et al., 2018)

Administration of LQ hydroethanolic extract at both doses significantly reduced elevated level of MDA, These results are in accordance with Shinde et al., (2016) who studied the antioxidant activity and antiproliferative action of methanolic extract of liquorice (Glycyrrhiza Glabra) in Hepg2 cell line and observed that liquorice treated HepG2 cells showed lower malondialdehyde (MDA) and higher glutathione and catalase levels as compared to only $\mathrm{H} 2 \mathrm{O} 2$ treated HepG2 cells where increased MDA production, decreased glutathione reductase and catalase production was observed.

TAA group showed a significant reduction in the CAT, GSH, SOD levels compared to control group and SL treated group as stander, our results are in accordance with those of Fazal et al., (2015) who studied oxidative stress and anti-oxidant status in thioacetamide-induced hepatotoxicity in albino wister rats and reported that TAA treatment results in increase lipid peroxidation and decrease GSH, SOD and CAT than the normal, and this produces oxidative stress in the liver. Whereas, LQ hydroethanolic extract ameliorate toxic effect of TAA, our results also were compatible with results detected by (Huo et al., 2011)

Our results showed that TAA administration significantly decreased the RBC count and Hb level however, the level of WBC count significantly increased $(\mathrm{P}<0.05)$ as compared to control and SL treated group as stander. The results observed agree with that reported by Al-Attar, (2011)who found that the administration of TAA to rats lead to significant decrease of RBC counts and Hb level and Abbasi et al., (2013) who reported that TAA significant increase of WBC counts in respect to control.

On the beneficial side oral administration of LQ before intrapertonial injection of TAA, showed a significant improvement in hematological parameters increase in red blood cells, hemoglobin level; and significant decrease in white blood cells this result was in harmony with that reported by Maksoud et al., (2019) who evaluate the ameliorative effect of liquorice extract versus silymarin in experimentally induced chronic hepatitis in rats.

Our histopathological examination showed that liver of TAA intoxicated rat showed inflammatory cells infiltration with fine fibroblastic cells proliferation were dividing the parenchyma into lobules in association with dilatation in the central vein. The portal area showed dilatation in the portal vein and inflammatory cells infiltration while the surrounding hepatocytes showed degenerative change. All these observed result was in harmony with that detected by Salam et al., (2013) who reported that Liver sections from rats given thioacetamide only showed loss of hepatic architecture.Hydropic degeneration of the hepatocytes, inflammatory cell infiltration in the portal area and thickness of the interlobular septum were seen. The benefits of LQ hydroethanolic extract are confirmed by histopathalogical observations, oral administration of LQ concurrently with TAA results in great repairing in tissue damage occurred due to TAA adminsteration.LQ significantly reduced the necroinflammatory scores and the extent of fibrosis that induced by TAA, this results were in agreement with El-Magd et al., (2015) who reported that treatment with GL, u-3 or their combination prevented the increase in NF-kB, so they prevented the development of liver fibrosis and necroinflammation.

\section{Conclusion}

The present study proved that LQ hydroethanolic extract especially at dose of $200 \mathrm{mg} / \mathrm{kg}$ b.wt can prevent hepatotoxicity and hematotoxicity induced by TAA in rats. This finding strongly supports the traditional use of this plant for hepatoprotective and hematinic actions. In addition, the antioxidant potentials of LQ were well supported with the reduction in hepatic MDA and increased level of reduced GSH, CAT, and SOD. In addition LQ hydroethanolic extract is non-toxic and showed no alteration in liver biomarkers, supported with the reduction in hepatic AST, ALT, ALP and increased level of reduced serum total protein and albumin.

\section{Acknowledgements}

Authors would like to express their deepest gratitude and sincere thanks to Prof. Dr. Abubakr M. El-Mahmoudy, Professor of Pharmacology Dept. Faculty of Veterinary Medicine, Benha University for his guidance for liquorice extraction.

And Prof. Dr. Adel Bakeer Kholoussy, Professor of Pathology, Cairo University for his help in histopathology examination.

\section{Funding: no funding sources}

Ethical approval: Rats were treated in accordance with the Guidelines for Animal Experimentation of the Ethics Review Committee of the Faculty of Veterinary Medicine, Benha University, Egypt.

\section{References}

[1] Abbasi MH, Akhtar T, Malik IA, Fatima S, Khawar B, Mujeeb KA, Mustafa G, Hussain S, Iqbal J, Sheikh N (2013). Acute and chronic toxicity of thioacteamide and alterations in blood cell indices in rats. https://doi.org/10.4236/jct.2013.41032.

[2] Adhikari M, Arora R (2016). The flavonolignan-silymarin protects enzymatic, hematological, and immune system against $\gamma$-radiation-induced toxicity. Environmental toxicology 31, 641-654. https://doi.org/10.1002/tox.22076.

[3] Aebi H (1984). [13] Catalase in vitro. In: Methods in enzymology: Elsevier. p 121-126. https://doi.org/10.1016/S0076-6879(84)05016-3.

[4] Al-Attar AM (2011). Hepatoprotective Influence of Vitamin C on Thioacetamide - induced Liver Cirrhosis in Wistar Male Rats. Journal of pharmacology and toxicology 6, 218-288. https://doi.org/10.3923/jpt.2011.218.233.

[5] Al-Naqeeb MA, Thomson M, Al-Qattan K, Kamel F, Mustafa T, Ali M (2003). Biochemical and histopathological toxicity of an aqueous extract of ginger in female rats. Kuwait journal of science and engineering 30, 35-48.

[6] Amacher DE (1998). Serum transaminase elevations as indicators of hepatic injury following the administration of drugs. Regulatory toxicology and pharmacology 27, 119-130. https://doi.org/10.1006/rtph.1998.1201.

[7] Bashandy SA, Ebaid H, Moussa SAA, Alhazza IM, Hassan I, Alaamer A, Al Tamimi J (2018). Potential effects of the combination of nicotinamide, vitamin B2 and vitamin C on oxidative-mediated hepatotoxicity induced by thioacetamide. Lipids in Health and Disease 17, 29. https://doi.org/10.1186/s12944-018-0674-z.

[8] Beutler E (1963). Improved method for the determination of blood glutathione. J. lab. clin. Med. 61, 882-888.

[9] Biomy ES, El-Sayed MG, El-Komy AA (2018). Phytochemicals and protective effects of Moringa oleifera seed extract on CCl4-induced hepatotoxicity and hemotoxicity in rats. International Journal of Basic \& Clinical Pharmacology 7, 1. https://doi.org/10.18203/2319-2003.ijbcp20184838.

[10] Das K (2014). Hepatoprotective and antioxidant activity of Lannea coromandelica Linn. on thioacetamide induced hepatotoxicity in rats. International letters of natural sciences 3 . 
[11] Dastagir G, Rizvi MA (2016). Glycyrrhiza glabra L.(Liquorice). Pakistan Journal of Pharmaceutical Sciences 29.

[12] Doumas BT, Watson WA, Biggs HG (1971). Albumin standards and the measurement of serum albumin with bromcresol green. Clinica chimica acta 31, 87-96. https://doi.org/10.1016/0009-8981(71)90365-2.

[13] El-Magd NFA, El-Karef A, El-Shishtawy MM, Eissa LA (2015). Hepatoprotective effects of glycyrrhizin and omega-3 fatty acids on Nuclear Factor-kappa B pathway in thioacetamide-induced fibrosis in rats. Egyptian Journal of Basic and Applied Sciences 2, 65-74. https://doi.org/10.1016/j.ejbas.2014.12.005.

[14] Fazal Y, Fatima SN, Shahid SM, Mahboob T (2015). Effects of curcumin on angiotensin-converting enzyme gene expression, oxidative stress and anti-oxidant status in thioacetamide-induced hepatotoxicity. Journal of the Renin-Angiotensin-Aldosterone System 16, 1046-1051. https://doi.org/10.1177/1470320314545777.

[15] Gheith I, Abubakr E-M (2019). Hepcidin-orchestrated Hemogram and Iron Homeostatic Patterns in Two Models of Subchronic Hepatic injury. Biomedical and Environmental Sciences 32, 153-161.

[16] Goorani S, Morovvati H, Seydi N, Almasi M, Amiri-Paryan A, Nazari F, Zangeneh MM, Zangeneh A (2019). Hepatoprotective and cytotoxicity properties of aqueous extract of Glycyrrhiza glabra in Wistar rats fed with high-fat diet. Comparative Clinical Pathology 28 , $1305-1312$. https://doi.org/10.1007/s00580-019-02939-6.

[17] Harborne JB (1973). A guide to modern techniques of plant analysis: Chapman and Hall.

[18] Haussament T (1977). Quantitative determination of serum alkaline phosphatase. Clin. Chem. Acta 35, $271-273$.

[19] Huo HZ, Wang B, Liang YK, Bao YY, Gu Y (2011). Hepatoprotective and antioxidant effects of licorice extract against CCl4-induced oxidative damage in rats. International Journal of Molecular Sciences 12, 6529-6543. https://doi.org/10.3390/ijms12106529.

[20] Jing J, Zhao J, Hua B, Xue M, Zhu Y, Liu G, Wang Y, Peng X (2015). Inhibitory effect of flavonoids from Glycyrrhiza uralensis on expressions of TGF- $\beta 1$ and Caspase- 3 in thioacetamide-induced hepatic fibrosis in rats. Zhongguo Zhong yao za zhi= Zhongguo zhongyao zazhi= China journal of Chinese materia medica 40, 3034-3040.

[21] Kabiri N, Ahangar-Darabi M, Setorki M, Rafieian-kopaei M (2013). The effect of silymarin on liver injury induced by Thioacetamide in rats. Journal of HerbMed Pharmacology 2, 29-33.

[22] Maksoud HA, Magid ADA, Mostafa Y, Elharrif MG, Sorour RI, Sorour MI (2019). Ameliorative effect of liquorice extract versus silymarin in experimentally induced chronic hepatitis: A biochemical and genetical study. Clinical Nutrition Experimental 23, 69-79. https://doi.org/10.1016/j.yclnex.2018.10.005.

[23] Nishikimi M, Rao NA, Yagi K (1972). The occurrence of superoxide anion in the reaction of reduced phenazine methosulfate and molecular oxygen. Biochemical and biophysical research communications 46, 849-854. https://doi.org/10.1016/S0006-291X(72)80218-3.

[24] Ohkawa H, Ohishi N, Yagi K (1979). Assay for lipid peroxides in animal tissues by thiobarbituric acid reaction. Analytical biochemistry 95, 351358. https://doi.org/10.1016/0003-2697(79)90738-3.

[25] Raj P, Nitesh K, Chandrashekhar H, Rao CM, Rao JV, Udupa N (2010). Effect of lecithin and silymarin on d-galactosamine induced toxicity in isolated hepatocytes and rats. Indian Journal of Clinical Biochemistry 25, 169-174. https://doi.org/10.1007/s12291-010-0031-0.

[26] Rasool M, Iqbal J, Malik A, Ramzan HS, Qureshi MS, Asif M, Qazi MH, Kamal MA, Chaudhary AGA, Al-Qahtani MH (2014). Hepatoprotective effects of Silybum marianum (Silymarin) and Glycyrrhiza glabra (Glycyrrhizin) in combination: a possible synergy. Evidence-Based Complementary and Alternative Medicine 2014. https://doi.org/10.1155/2014/641597.

[27] Reitman S, Frankel S (1957). A colorimetric method for the determination of serum glutamic oxalacetic and glutamic pyruvic transaminases. American journal of clinical pathology 28, 56-63. https://doi.org/10.1093/ajcp/28.1.56.

[28] Salam OA, Mohammed N, Sleem A, Farrag A (2013). The effect of antidepressant drugs on thioacetamide-induced oxidative stress. Eur. Rev. Med. Pharmacol. Sci 17, 735-744.

[29] Shalaby MA, Ibrahim HS, Mahmoud EM, Mahmoud AF (2004). Some effects of Glycyrrhiza glabra (liquorice) roots extract on male rats. Egyptian Journal of Natural Toxins 1, 83-94.

[30] Shinde DB, Koratkar SS, Sharma N, Shitole AA (2016). Antioxidant activity and antiproliferative action of methanolic extract of liquorice (Glycyrrhiza glabra) in HepG2 cell line. Int. J. Pharm. Pharm. Sci 8, 293-298. https://doi.org/10.22159/ijpps.2016v8i9.11954.

[31] Thakur D, Jain A, Ghoshal G (2016). Evaluation of phytochemical, antioxidant and antimicrobial properties of glycyrrhizin extracted from roots of Glycyrrhiza Glabra.

[32] Wallace M, Hamesch K, Lunova M, Kim Y, Weiskirchen R, Strnad P, Friedman S (2015). Standard operating procedures in experimental liver research: thioacetamide model in mice and rats. Laboratory animals 49, 21-29. https://doi.org/10.1177/0023677215573040. 